\title{
Complete Pyriform Sinus Fistulas: Case Series and Review of Literature
}

\author{
${ }^{1}$ Sandeep Bansal, ${ }^{2}$ Abhishek Jaswal, ${ }^{3}$ Ashok K Gupta \\ ${ }^{1}$ Assistant Professor, Department of Otolaryngology, Head and Neck Surgery, Postgraduate Institute of Medical \\ Education and Research, Chandigarh, India \\ ${ }^{2}$ Senior Resident, Department of Otolaryngology, Head and Neck Surgery, Postgraduate Institute of Medical \\ Education and Research, Chandigarh, India \\ ${ }^{3}$ Professor and Head, Department of Otolaryngology, Head and Neck Surgery, Postgraduate Institute of Medical \\ Education and Research Chandigarh, India
}

Correspondence: Sandeep Bansal, Assistant Professor, Department of Otolaryngology, Head and Neck Surgery, Postgraduate Institute of Medical Education and Research, Chandigarh, India, e-mail: drsandeepb@ rediffmail.com

\begin{abstract}
Pyriform sinus fistula belongs to the rarest group of cervical fistulae accounting for 3 to $10 \%$ of all branchial anomalies. ${ }^{1}$ The first clinical and embryological studies were described in the early seventies by Sandborn and Tucker, but embryological knowledge in this field remains incomplete. Children and adults usually complaint of painful neck swelling accompanied by fever that is preceded by upper respiratory infection, otalgia and odynophagia. Neonates and infants may have respiratory distress, sometimes with stridor, due to tracheal compression by the abscess. ${ }^{1,5,6}$ However, the most common mode of presentation is the recurrent episodes of acute thyroiditis. Eighty percent of patients with recurrent acute suppurative thyroiditis due to persistent pyriform sinus fistula present during the first decade of life. Making the distinction between third and fourth arch fistulas is difficult on clinical grounds alone and hence they are often collectively termed pyriform sinus fistula. O wing to the rarity of the condition and varied clinical presentation, diagnosis and ultimate management is often delayed leading to undue morbidity to the patient and professional frustration for the treating surgeon. We, hereby, present a case series of three classical cases of complete pyriform sinus fistulas with review of available literature in an attempt to clarify issues regarding presentation, diagnosis and management of this condition.
\end{abstract}

Keywords: Pyriform sinus fistula, Complete excision, Excision.

\section{INTRODUCTION}

Pyriform sinus fistula belongs to the rarest group of cervical fistulae accounting for 3 to $10 \%$ of all branchial anomalies. ${ }^{1}$ The first clinical and embryological studies were described in the early seventies by Sandborn and Tucker, but embryological knowledge in this field remains incomplete. ${ }^{2-4}$ Children and adults usually complaint of painful neck swelling accompanied by fever that is preceded by upper respiratory infection, otalgia and odynophagia. $N$ eonates and infants may have respiratory distress, sometimes with stridor, due to tracheal compression by the abscess. ${ }^{1,5,6}$ However, the most common mode of presentation is the recurrent episodes of acute thyroiditis. Eighty percent of patients with recurrent acute suppurative thyroiditis due to persistent pyriform sinus fistula present during the first decade of life. These fistulas are almost always left sided (92\%). ${ }^{7,8}$ Treatment has traditionally involved cannulation of the pyriform sinus fistula, if identified during direct laryngoscopy to aid complete surgical excision followed by excision of the sinus tract with partial thyroidectomy, if the thyroid gland is involved. ${ }^{1,6}$ Owing to the rarity of the condition and varied clinical presentation, diagnosis and ultimate management is often delayed leading to undue morbidity to the patient and profession frustration for the treating surgeon. We, hereby, present a case series of three classical cases of pyriform sinus fistula with review of available literature in an attempt to clarify issues regarding presentation, diagnosis and management of this condition.

\section{CASE REPORT}

A 9-year-old male presented with the history of mucopurulent discharge from a sinus opening on left-side of neck for 1 year. There was history of recurrent left-sided neck swelling and pain preceding the development of the sinus. O ne such episode was treated by a local physician by incision and drainage resulting in the development of the sinus. On examination, there was a fistulous opening along the anterior border of sternocliedomastoid at the junction of upper 2/3rd and lower $1 / 3$ rd with overlying scar mark of previous incision drainage. There was slight tenderness on palpation of ipsilateral thyroid gland. Thyroid function test was however normal. CT scan reveal ed a tract running from the external opening toward the medial portion of left thyroid Iamina. U Itrasound of neck done during acute stage reveal ed heterogeneous echotexture of the left thyroid lobe with presence of air pockets in the soft tissue surrounding the upper pole of left thyroid. The acute episode was treated with systemic antibiotics and nasogastric feeding with an expectation of spontaneous closure of the fistula. H owever, removal of nasogastric tube resulted in recurrence of the discharge. Patient was worked up to undergo surgery with a provisional diagnosis of pyriform sinus fistula. Direct 


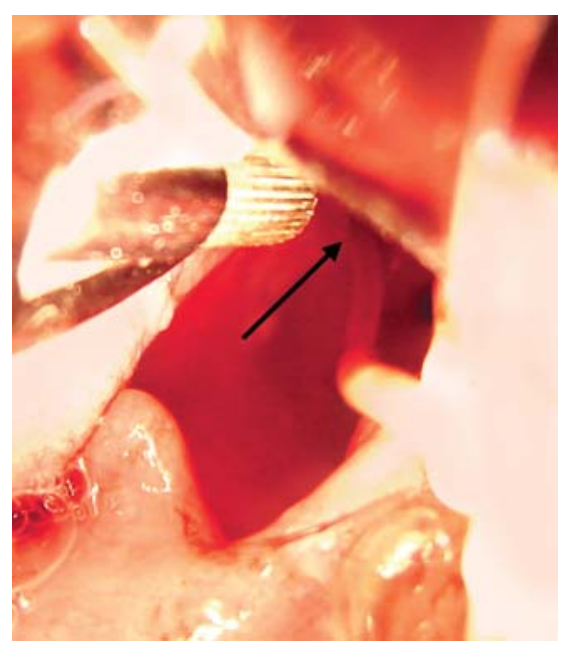

Fig. 1: The opening in apex of pyriform sinus (black arrow) cannulated using infant feeding tube

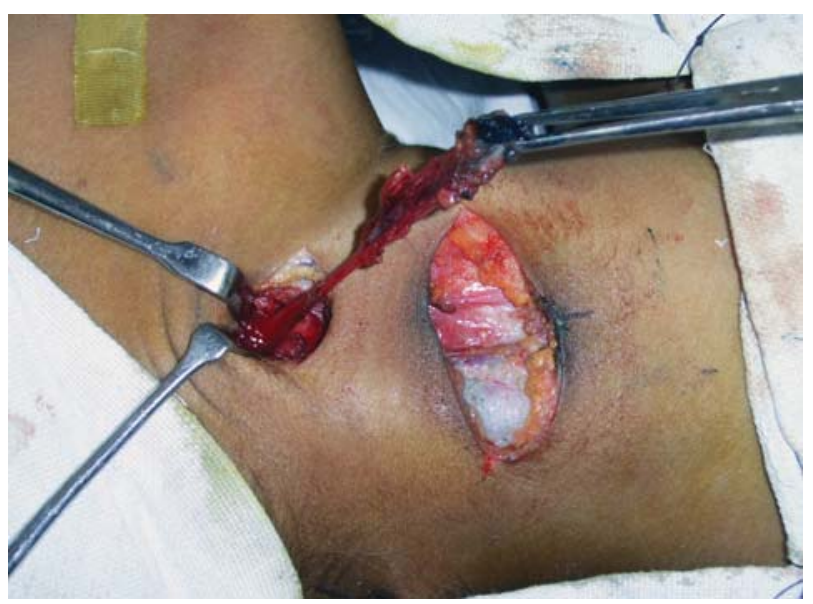

Fig. 2: Excision of fistulous tract using step-ladder incisions

laryngoscopy done prior to surgical excision revealed an opening at the apex of left pyriform sinus with spillage of methylene blue dye into the hypopharynx. The patient was operated with a tentative diagnosis of a pyriform sinus fistula. The sinus tract was cannulated using infant feeding tube (Fig. 1). During operation, attempt at cannulation of the tract failed due to intense fibrosis and step-ladder incision was used due to long length of the tract (Fig. 2). The tract was seen running in close contact with the upper pole of left thyroid lobe from which it can be easily separated. A part from slight induration left lobe was within normal limits so it was decided not to remove the gland. Pyriform sinus opening was closed in two layers. Patient was kept on nasogastric feeding for 7 days before commencing oral feeds. I mmediate postoperative period was uneventful. But patient developed left-sided painful neck swelling 2 months postoperative, there was no recurrence of fistula and the patient was managed conservatively.

The details of the cases 2 and 3 are given in Table 1 .

\section{DISCUSSION}

Pyriform sinus fistulas are known to originate from an abnormality of pharyngobranchial sinus development in the fourth week of fetal life. A fistula formed from the third branchial arch has its external opening in the same area as the second branchial fistula. The tract passes deep to the platysma, ascending along the common carotid sheath, passing behind the common and internal carotid artery. The tract crosses the hypogl ossal nerve but will not ascend above the glossopharyngeal nerve or the stylopharyngeus muscle and is superficial to the superior laryngeal nerve. The internal opening is in the pyriform sinus. The theoretical course of a fourth branchial fistula would originate at the anterior border of the lower portion of the sternocleidomastoid muscle. It would also pierce the platysma, ascend along the carotid sheath, pass under the superior laryngeal nerve, but over the recurrent laryngeal and hypoglossal nerves. A fourth branchial pouch sinus would then dip back into the chest to pass around the aortic arch on the left and the subclavian artery on the right. Finally, it would ascend to enter thelarynx near the cricothyroid joint or through the lower horn of the thyroid cartilage, pass through the inferior constrictor and enter the apex of the pyriform sinus. ${ }^{9,10}$ It is probably due to the complex and convoluted course that a complete fourth branchial fistula has yet to be reported. Because of the similarity in their course, making the distinction between third and fourth arch fistulas is difficult on clinical grounds alone. In fact, the diagnosis is usually made during dissection. The key difference between the two is the relationship to the superior and recurrent laryngeal nerves. A third branchial fistula will pass superficial to both the superior and recurrent laryngeal nerves. A fourth branchial fistula theoretically will pass deep to the superior laryngeal nerve but superficial to the recurrent laryngeal nerve. ${ }^{11,12}$ True distinction is however not possible even on dissection in all cases owing to the fibrosis secondary to the recurrent neck infection as was seen in two of our patients where true distinction could not be made regarding the relations of tract. In third case the tract could clearly be demonstrated to pass above recurrent laryngeal nerve. This confusing relationship and failure to demonstrate the true course along with similar clinical course of both third and fourth fistula prompt the use of terminology of pyriform sinus fistula.

A pproximately, $92 \%$ of fourth arch anomalies present on the left which was true in our case where all the patients had fistula on left side, and males are slightly more prone as was seen in our case where all the patients were male. These anomalies have been diagnosed at ages ranging from birth to adulthood. ${ }^{1,4,11-16}$ Children and adults usually have painful neck swelling accompanied by fever that is preceded by upper respiratory infection, otalgia and odynophagia. $\mathrm{N}$ eonates and infants may have respiratory distress, sometimes with stridor, due to tracheal compression by the abscess. A round $67 \%$ of cases present with acute suppurative thyroiditis, in the remainder either a lateral neck mass or a cervical fistula. A bout $50 \%$ of patients have three or more episodes of thyroiditis before the diagnosis is 
Table 1: Details of cases

$\begin{array}{llll}\text { Age } & 9 \text { years } & 12 \text { years } & 11 \text { years } \\ \text { Sex } & \text { M } & \text { M } & \text { M } \\ \text { First symptom age } & 8 \text { years } & 10 \text { years } & 10 \text { years } \\ \text { Diagnosis and management age } & 9 \text { years } & 12 \text { years } & 11 \text { years } \\ \text { Side } & \text { Left } & \text { Left } & \text { Left } \\ \text { Symptoms } & \text { Recurrent thyroiditis, neck } & \text { Recurrent discharge } & \text { Recurrent } \\ & \text { swelling, purulent } & \text { discharge from left- } \\ & \text { discharge } & \text { with intermittent } & \text { sided sinus } \\ \text { Previous drainage or excision } & \text { Yes 1 } & \text { acute exacerbation } & \text { No } \\ \text { Thyroid lobectomy required } & \text { Not required } & \text { Yes 2 } & \text { Not required } \\ \text { Complications } & \text { Nil } & \text { Not required } & \text { Nil } \\ \text { Recurrence } & \text { Nil } & \text { Nil } & \text { Nil }\end{array}$

made. ${ }^{7,8,17-27}$ A verage age of presentation in our case was 10.6 years with complaint of recurrent discharge from a fistulous opening in neck being most common symptom. Classical symptoms of recurrent thyroiditis were present in only one patient (Table 1).

Diagnosis of pyriform sinus fistula hinges on the ability to demonstrate a sinus or fistula originating from the pyriform sinus. A barium esophagogram may reveal a sinus tract. A tract originating in the pyriform sinus on barium esophagogram indicates a third or fourth branchial sinus. A study by Lin and Wang reported identification of the sinus tract by barium studies in almost every case. ${ }^{28}$ How ever, in another report of patients with pyriform sinus fistulas confirmed by direct laryngoscopy, barium esophagograms detected the anomaly in only $50 \%$ of cases. ${ }^{29}$ B arium esophagogram as a diagnostic modality was not frequently used in our case series and inconclusive result was obtained in case where it was used.

Both CT and M R studies were excellent in delineating inflammatory lesions along the tract, even when the sinus or fistulous tract was not clinically apparent. But CT was superior in detecting air density at the sinus or fistulous tract as well as in depicting thyroid gland involvement as a loss of high density in the affected thyroid gland. The resolution of $C T$ is also superior to that of $M R$ imaging. Obtaining a CT scan immediately after barium swallow may increase the sensitivity of the scan by highlighting the sinus tract. Air, fluid or cartilage may all indicate the site of the lesion. Inflammation of the pyriform sinus, strap muscle layer, thyroid gland and perithyroid area could indicate an infected pyriform sinus tract. Ultrasound may be useful in showing a liquid/air collection near the cricothyroid joint. ${ }^{29}$ CT scan findings were contributory in only one of our cases where it can demonstrate the tract but limitation of its resolution hampered the conclusive diagnosis which ultimately required a direct laryngoscopy and demonstration of fistulous tract using dye injection at the time of surgery. Ultrasound finding during acute stage, however, is more specific in pointing to the diagnosis, demonstrating limited involvement of upper pole along with air pockets and air fluid level as was seen in one of our cases.

The definite diagnosis, however, hinges upon the demonstration of the internal opening in the pyriform fossa on direct laryngoscopy as could be located in all of our cases. The identification of the fistulous tract can be further enhanced by injection of dye and demonstrating the spillage in hypopharynx and catheterizing the opening with a soft rubber catheter or infant feeding tube or size 3 Fogarty catheter or with the spring gui de wire of a vascular catheter.

Treatment is similar to other branchial anomalies. Complete surgical excision with repair of pyriform sinus opening is curative as was done in our cases. Other modalities, such as aspiration or incision and drainage, have been shown to be associated with an increased risk of recurrence and complications such as hemorrhage, wound infection, cranial nerve injury and airway obstruction. If the tract passes through the left thyroid lobe and causes frequent thyroiditis, a thyroid lobectomy may be necessary. The tract, how ever, could easily be separated from the thyroid lobe in all of our cases eliminating the need for thyroidectomy. Recently, cases of chemocauterization with trichloracetic acid and silver nitrate have been reported, but data about long-term follow-up and complications are lacking. ${ }^{30,31}$

\section{CONCLUSION}

Pyriform sinus fistula bel ongs to the rarest group of cervical fistulae with varied clinical presentations. M aking the distinction between third and fourth arch fistulas is difficult on clinical grounds alone and hence, they are often collectively termed pyriform sinus fistula. Owing to the rarity of the condition and varied clinical presentation, the diagnosis and ultimate management is often delayed with most patients undergoing multiple surgical procedures. Diagnosis though simply based upon the demonstration of a fistulous opening in pyriform sinus but it needs high degree of suspicion on the part of treating surgeon. Once diagnosis is made, treatment is complete excision of the fistulous tract with closure of the pyriform sinus opening. Management 
of the thyroid which is commonly involved in the condition is, however, based upon the intraoperative evaluation and a conservative approach is often warranted as the tract runs in close proximity but not through the thyroid tissue in most cases.

\section{REFERENCES}

1. Y ang C, Cohen J, Everts E, et al. Fourth branchial arch sinus: Clinical presentation, diagnostic workup, and surgical treatment. L aryngoscope 1999;109:442-46.

2. Sandborn WD, Shafer AD. A branchial cleft cyst of fourth pouch origin. J Pediatr Surg 1972;7:82.

3. Tucker HM , Skolnick M L. Fourth branchial cleft (pharyngeal pouch) remnant. Trans A m A cata Ophthalmol Otolaryngol 1973;77:368-71.

4. L iston SL. Fourth branchial fistula. Otolaryngol Head N eck Surg 1981;89:520-22.

5. Torsiglieri A J J r, Tom LW, Ross A J III, W etmore RF, Handler SD, Potsic P. Pediatric neck masses: Guidelines for evaluation. Int J Pediatr Otorhinolaryngol 1988;16(3):199-210.

6. Choi SS, Zalzal GH. B ranchial anomalies: A review of 52 cases. Laryngoscope 1995;105(9 Pt 1):909-13.

7. Jane A Cases, Bruce M W enig, Carl E Silver, et al. Recurrent acute suppurative thyroiditis in an adult due to a fourth branchial pouch fistula. The Journal of Clinical Endocrinology and M etabolism 2000;85(3):953-56.

8. Tovi F, Gatot A, Bar-Ziv J, Y anay I. Recurrent suppurative thyroiditis due to fourth branchial pouch sinus. Int J Pediatr Otolaryngol 1985;9:89-96.

9. Moore KL, Persaud TVN. Before we are born. Essentials of embryology and birth defects (5th ed). Philadel phia, PA : Saunders; 1998;197-211.

10. Lee FP. Occult congenital pyriform sinus fistula causing recurrent left lower neck abscess. Head Neck 1999;21:671-76.

11. Nicollas R, Ducroz V, Garabedian EN, Triglia JM. Fourth branchial pouch anomalies: A study of six cases and review of the literature. Int J Pediatr. Otorhinolaryngol 1998;44(1):5-10.

12. Rosenfeld RM, Biller HF. Fourth branchial pouch sinus: Diagnosis and treatment. Otolaryngol Head Neck Surg 1991;105(1):44-50.

13. M andell DL. Head and neck anomalies related to the branchial apparatus. Otolaryngol Clin North A m 2000;33(6):1309-32.

14. Liberman M, Kay S, Emil S, Flageole H, N guyen LT, Tewfik $T L$, et al. Ten years of experience with third and fourth branchial remnants. J Pediatr Surg 2000;37(5):685-90.

15. M akino S, Tsuchida Y, Y oshioka H, Saito S. The endoscopic and surgical management of pyriform sinus fistulae in infants and children. J Pediatr Surg 1986;21:398-401.
16. M iller M B, Cohn AS. Case report: Fourth branchial pouch sinus. Ear Nose Throat J 1993;72:356-58.

17. Raven RW. Pouches of the pharynx and esophagus with special reference to the embryological and morphological aspects. $\mathrm{Br}$ J Surg 1933;21:235-56.

18. Takai S, M atsuzuka F, M iyauchi A, K uma K, K osaki G. Internal fistula as a route of infection in acute suppurative thyroiditis. L ancet 1979;1:751-52.

19. M iyauchi A, M atsuzuka F, Takai S, K uma K, K osaki G. Pyriform sinus fistula. Arch Surg 1981;116:66-69.

20. Nonomura N, Ikarashi F, Fujisaki T, Nakano Y. Surgical approach to pyriform sinus fistula. A m J Otolaryngol 1993; 14:111-15.

21. Y amashita J, O gawa M , Y amashita S, Saishoji T, N omura K, Tsuruta J. A cute suppurative thyroiditis in an asymptomatic woman: A $n$ atypical presentation simulating thyroid carcinoma. Clin Endocrinol 1994;40:145-50.

22. Himi $T, K$ ataura $A$. Distribution of $C$ cells in the thyroid gland with pyriform sinus fistula. Otolaryngol Head Neck Surg 1995;112:268-73.

23. Bar-Ziv J, Slasky BS, Sichel JY , L ieberman A, K atz R. B ranchial pouch sinus tract from piriform fossa causing acute suppurative thyroiditis, neck abscess, or both: CT appearance and the use of air as a contrast agent. Am J Radiol 1996;167:1569-72.

24. M iller D, Hill JL, Sun C, O'B rien DS, Haller JA. The diagnosis and management of pyriform sinus fistulae in infants and young children. J Pediatr Surg 1983;18:377-81.

25. Shaw A. A cute suppurative thyroiditis. A m J Dis Child 1979;133:757.

26. Skuza K, Rapaport R, Fieldman R, Goldstein S, M arquis J. Recurrent acute suppurative thyroiditis. J Otolaryngol 1991;20:126-29.

27. B arker GJ , Spitz L. R ecurrent left cervical abscess secondary to persistent pyriform sinus fistula. JR Coll Surg Edinb. 1998;43:125-26.

28. Lin N, W ang KL. Persistent third branchial apparatus. J Pediatr Surg 1991;26(6):663-65.

29. Park SW, H an M H, Sung M H, K im IO, K im K H, Chang K H, et al. Neck infection associated with pyriform sinus fistula: Imaging findings. A m J Neuroradiol 2000;21(5):817-22.

30. Jordan JA, Graves JE, M anning SC, et al. Endoscopic cauterization for treatment of fourth branchial cl eft sinuses. A rch Otolaryngol Head N eck Surg 1998;124:1021-24.

31. Stenquist $M$, J uhlin C, A strom $G$, et al. Fourth branchial pouch sinus with recurrent deep cervical abscesses successfully treated with trichloroacetic acid cauterization. Acta Otolaryngol 2003;123:879-82. 